\title{
AGRESSIVIDADE INFANTIL NO CONTEXTO ESCOLAR: AS POSSIBILIDADES DE AUXÍLIO PROPORCIONADAS PELA LUDICIDADE
}

\author{
Rafaela Reginato Hosokawa; Fabio Camargo Bandeira Villela \\ Universidade Estadual Paulista - UNESP, Faculdade de Ciências e Tecnologia - FCT, Departamento de Educação. E- \\ mail: rafaela_reginato@hotmail.com
}

\section{RESUMO}

O presente artigo trata de um projeto de extensão e pesquisa, realizado em uma escola de Ensino Fundamental da rede pública do município de Presidente Prudente-SP. O referido projeto compreende que conflitos internos e dificuldades emocionais na infância podem ser responsáveis por dificuldades de relacionamento em sala de aula. Nessa perspectiva, se propõe a investigar a possibilidade de se contribuir para a resolução desses conflitos, obtendo-se uma consequente melhoria no comportamento dos alunos, por meio de atividades lúdicas. Ao participar do referido projeto, deparou-se com o caso de um garoto considerado agressivo por sua professora e buscou-se investigar se o brincar e o suporte emocional oferecido ao aluno teria potencial para minimizar sua conduta agressiva. A pesquisa foi realizada com base nos pressupostos da pesquisa qualitativa, tendo como referencial a investigação das manifestações da criança, pensadas a partir das contribuições da teoria psicanalítica winnicottiana.

Palavras-chave: Agressividade infantil, brincar, Winnicott.

\section{INFANT AGGRESION IN THE CONTEXT OF SCHOOL: THE POSSIBILITIES OF RELIEF BEING PROVIDED BY PLAY}

\begin{abstract}
The present article concerns a research and extension project carried out in a public elementary school in the municipality of Presidente Prudente, São Paulo State. The project takes account of the fact that internal conflicts and emotional difficulties in infancy can cause problems in relationships in the classroom. Against this background, it was proposed to investigate the possibility of contributing to resolving these conflicts, gaining a consequent improvement in children's behavior, through play activities. Through taking part in the project, the case of a boy considered aggressive by his teacher came to light and it was investigated whether play and emotional support given to the pupil had the potential to minimize his aggressive conduct. The investigation was carried out on assumptions of qualitative research, taking as reference research into children's tantrums stemming from the thinking of the theoretical psychoanalyst Donald Winnicott.
\end{abstract}

Keywords: Infantile aggression, playing, Winnicott

\section{INTRODUÇÃO}

O presente artigo se refere a um projeto de pesquisa e extensão denominado Brinquedoteca escolar, que é desenvolvido em uma escola de Ensino Fundamental I, na rede pública do município de Presidente Prudente.

O projeto em questão compreende que as crianças em idade escolar enfrentam conflitos internos que podem ser responsáveis por dificuldades de relacionamento em sala de aula. Nesse sentido, propõe-se a investigar a possibilidade de se contribuir para a resolução desses conflitos, obtendo-se uma consequente melhoria na conduta dos alunos, por meio de atividades lúdicas, tendo como suporte a teoria winnicottiana acerca do desenvolvimento infantil e dos benefícios do brincar.

Ao participar do referido projeto, deparou-se com $o$ caso de um garoto considerado agressivo por sua professora e, a partir desse, procurou-se investigar se o brincar e o suporte emocional oferecido no decorrer das 
atividades lúdicas tiveram potencial para minimizar a conduta agressiva da criança.

O objetivo do presente trabalho é investigar as possibilidades de compreensão de uma criança que apresenta conduta agressiva e de intervenção junto a ela através do desenvolvimento de atividades lúdicas.

\section{METODOLOGIA}

A presente pesquisa se insere em uma abordagem qualitativa que, de acordo com o que apresentam Bogdan e Biklen (1982 apud LÜDKE; ANDRÉ,1986, p.13), "[...]envolve a obtenção de dados descritivos, obtidos no contato direto do pesquisador com a situação estudada, enfatiza mais o processo do que o produto e se preocupa em retratar a perspectiva dos participantes".

Trata-se de uma pesquisa de tipo estudo de caso, que tem como referencial a investigação das manifestações da criança, do ponto de vista da teoria psicanalítica. $O$ projeto tem como suporte teórico a teoria psicanalítica de Winnicott sobre a importância do brincar para a simbolização e resolução de conflitos infantis.

O sujeito da pesquisa é uma criança do sexo masculino, que estuda em uma escola pública da rede municipal de Presidente Prudente e tem nove anos de idade. $\mathrm{O}$ aluno foi encaminhado ao projeto pela escola, pelo fato de possuir grande dificuldade para se relacionar com os colegas, pois apresentava momentos de agressividade.

Durante as atividades lúdicas desenvolvidas com o aluno, a pesquisadora disponibiliza duas caixas: uma com diversos brinquedos e outra caixa com materiais para desenhar e livros.

Por intermédio do brinquedo escolhido e da atividade lúdica com ele desenvolvida pela criança, a pesquisadora se sensibilizava com o que estava sendo simbolizado e as transferências que apareciam durante o encontro lúdico, associando essas manifestações a possíveis conteúdo internos da criança. Os encontros duravam em média cinquenta minutos e ocorreram na própria escola em que o aluno estudava, durante o período de aula, no espaço da brinquedoteca, nos anos de 2013 e 2014.

$\mathrm{O}$ projeto foi aprovado pelo comitê de ética em pesquisa (CAAE: 26802314.8.0000.5402), e obteve a devida autorização dos pais. $O$ atendimento foi realizado pela pedagoga pesquisadora Rafaela Reginato Hosokawa e a apresentação dos atendimentos lúdicos à criança será feita em narrativa na primeira pessoa do singular.

\section{RESULTADOS}

Como foi expresso, neste trabalho será apresentado o caso de um garoto, que aqui será chamado Hugo (nome fictício). Os dados que serão apresentados a seguir foram obtidos nos encontros lúdicos realizados de 30/10/2013 à 28/11/2014, totalizando 25 encontros.

Hugo foi encaminhado ao projeto pela escola, por ser considerado uma criança com conduta agressiva. Conforme sua professora, o garoto apresentava dificuldade em se relacionar com os colegas devido à sua conduta agressiva, envolvia-se em confusões com frequência, tentando sempre solucionar as situações de conflito com o uso da força. Além de suas manifestações agressivas, a professora ressaltava a dificuldade do garoto em desempenhar atividades de leitura e escrita.

Em conversa com a mãe, esta informou que Hugo apresentava uma relação conturbada com o irmão mais velho, os dois costumavam brigar frequentemente. A mãe atribuía essas brigas a um possível ciúme que Hugo sente do irmão. Ela também considerava o menino agressivo.

Em nosso o primeiro encontro lúdico, Hugo mostrou-se bastante à vontade e contente em participar do projeto. O garoto estava encantado com a variedade de brinquedos e investigava tudo que havia na sala.

Hugo encontrou uma réplica de um navio e pegou-a para brincar. No navio havia um rato e, ao vê-lo, o garoto disse que tinha um rato de estimação que era bonzinho e obediente. Após isso, o menino criou uma brincadeira na qual havia um grupo de animais que brigavam entre si, dentre os quais estavam dois rinocerontes que, de acordo com Hugo, eram irmãos.

Em outro encontro, Hugo disse que apresentaria uma história utilizando os fantoches. Primeiramente ele contou a história da Chapeuzinho Vermelho com todos os momentos da história original. Após contá-la, Hugo pegou um fantoche de cachorro e começou a conversar comigo como se fosse o cachorro. Disse que havia sido abandonado por sua mãe, morava na rua e passava fome.

Em seguida, ele encontrou algumas fantasias para criança. Algumas eram pequenas e não lhe serviam. $O$ garoto vestiu uma fantasia de palhaço e também um vestido de bailarina. 
Contou que tinha um cavalo de estimação, enorme e bonito. Disse que cuidava dele, alimentava, dava banho e brincava. Pegou um cavalo de brinquedo na caixa e disse que era igual ao seu, só que aquele era de brinquedo e o seu não.

Hugo passou a contar histórias sobre seu cavalo nos encontros seguintes. Dizia que passeava com o cavalo e que ele era muito veloz. Aos poucos, deixou de falar do cavalo e se entreteve com outras atividades.

Após o período de férias escolares, os encontros são retomados. Hugo demonstra bastante alegria com a continuidade do projeto e certa surpresa e contentamento ao me ver, tanto que disse Você voltou!

Nos encontros lúdicos que ocorreram, o menino passou a construir cercados com peças de madeira e colocar os animais neles, dividindoos de acordo com o tamanho. Os cercados foram construídos de modo minucioso, para que nenhuma peça ficasse desalinhada. Nesse período, surgiu o interesse por jogos de cartas e tabuleiro, nos quais criava regras que 0 beneficiavam e trapaceava quando estava prestes a perder.

Interessou-se pelo livro João e o Pé de Feijão, solicitava a leitura e ouvia atentamente, ficando maravilhado pelas gravuras do pé de feijão, tanto que construiu um, utilizando blocos de madeira.

Durante os encontros seguintes, Hugo passou a construir prédios, cidades, fazendas e zoológico com as peças de madeira. Construía tudo minuciosamente, preocupava-se com cor e tamanho.

Na brincadeira de zoológico, Hugo disse que iria cuidar dos leões, porque eram muito perigosos. Entretanto, em certo momento da brincadeira, o menino disse que um leão havia arrancado seu braço, mas falou que não era preciso se preocupar, pois ele era forte, não sentia dores e iria colocar um braço de ferro. Em outro momento, os animais começaram a brigar e um tigre acabava matando uma girafa, então a mãe da girafa morta começava a chorar e Hugo dizia: Ela está muito triste.

Ao brincar de corrida com os carrinhos, o garoto explicava que os carrinhos estavam no deserto e eram muito velozes, o que acabava provocando colisões. Quando isso acontecia, Hugo dizia que era preciso levar os passageiros ao hospital, pois estavam feridos, e, assim fazia, sendo ele próprio o médico que cuidava das vítimas. Quando se tornava médico na brincadeira, o menino pegava uma maleta de brinquedo, na qual havia alguns instrumentos de médico, examinava o boneco e aplicava injeções.

Nesse momento dos encontros, notou-se que, nos jogos de competição, a derrota parecia não abalá-lo como antes, pois o menino mostrouse capaz de parabenizar o outro pela vitória, persistir na brincadeira mesmo quando estava perdendo, sem trapacear. Hugo também desenvolveu atividades com massinha, nas quais construía objetos e divertia-se misturando cores. Passou a se interessar, ainda, pela montagem de quebra-cabeças.

O menino desenhava e convidava-me para a atividade. Representava um sol, uma nuvem, uma árvore com um longo tronco, da qual caíam frutas vermelhas. Fazia, também, um rio com uma pessoa em um barco pescando. Quando questionado quem era o pescador, Hugo disse que era ele. Em seguida fez um arco-íris e, por fim, desenhou uma pessoa colhendo as frutas que caíam da árvore, dizendo que se tratava do irmão, pois este não teria coragem de pescar devido ao medo que tem de animais, conforme Hugo.

Em nosso último encontro o menino propôs brincar de comidinha. Finge que é um chefe de restaurante e fez diversos tipos de comida para mim.

Ao término do ano, a professora dizia observar maior tranquilidade e concentração nas atividades desempenhadas em sala de aula, contribuindo para o seu avanço na aprendizagem dos conteúdos escolares, bem como em seus relacionamentos interpessoais.

\section{DISCUSSÃO}

A partir do desenvolvimentos das atividades lúdicas, observou-se que, no início dos encontros, Hugo mostrava-se bastante satisfeito pela possibilidade de um momento lúdico e a relação conflituosa com o irmão logo evidenciouse na brincadeira com animais.

O menino apresentava relatos fantasiosos, quando dizia ter um rato e um cavalo, pois em entrevista com a mãe, ela contou ter apenas um cachorro, com o qual Hugo gosta de brincar. A fantasia é usada como forma de suportar a realidade externa ou refugiar-se dela, proporcionando alívio de suas angústias.

É possível notar que, a cada encontro, Hugo utilizava uma forma diferente para expressar suas angústias, anseios e emoções. Não 
havia fixação em uma determinada brincadeira, o que é bom, pois demonstra ser capaz de, por si só, elaborar maneiras diversas de manifestar sua realidade interior e de elaborar seus conflitos e ansiedades.

Ao contar a história do cachorrinho abandonado, acredita-se que o garoto tinha a intenção de expressar seu medo de ser abandonado ou rejeitado. Outro fato que chama a atenção é o fato de o garoto ter vestido a fantasia de bailarina, aliado, também, à história da Chapeuzinho vermelho contada por ele, que trata de questões ligadas à sexualidade. A fantasia de Hugo em relação ao cavalo se opõe a história do cachorro abandonado, pois, ao contrário deste, o cavalo é bem cuidado e alimentado. Assim, acredita-se que esta fantasia Ihe sirva de conforto em relação ao medo de ser abandonado, reforçando seu sentimento de segurança.

Retomar os atendimentos com o garoto, após o período de férias escolares, foi muito importante para ele, uma vez que isso, possivelmente, proporcionou impactos em sua confiança e diminuiu o temor de ser rejeitado ou abandonado. Assim, baseando-se na teoria winnicottiana, que defende que uma vez que o vínculo de confiança é estabelecido, ele deve ser estável e duradouro, acredita-se que a continuidade dos encontros trouxe benefícios para essa criança, ampliando os ganhos que ele já apresentou no ano anterior.

Hugo denota ser uma pessoa extremamente detalhista e metódica. Essa fixação pela organização pode ser entendida por uma tentativa de ordenar seu caos interno.

A leitura do livro João e o Pé de Feijão, escolhida por Hugo, trata de questões relacionadas ao desenvolvimento sexual e às fantasias fálicas e edípicas. Nota-se que a história traz certo alívio para o garoto, que se acalma e inicia uma brincadeira que tem relação com as fantasias fálicas, a construção de um pé de feijão, utilizando blocos de madeira.

Nos jogos de cartas e tabuleiro, o menino apresenta dificuldade em lidar com a perda, tanto que cria regras que o favorecem e trapaceia, de modo a garantir sua vitória. Com o decorrer dos encontros, Hugo abandona esse tipo de conduta, passando a aceitar a derrota, sem que isso lhe cause sofrimento considerável.

Nas atividades lúdicas, Hugo encontra uma maneira de lidar com a perda e de descarregar suas emoções e tendências agressivas, sem que ele se sinta culpado, proporcionando o alívio de suas tensões préconscientes e inconscientes e diminuindo o medo de suas tendências destrutivas. Ao brincar de zoológico, por exemplo, o menino expressa alguns aspectos relacionados ao amor e a agressão. Ao mesmo tempo em que demonstra preocupar-se comigo e cuida dos animais, manifesta conteúdos agressivos e ligados à morte. Hugo também busca reafirmar sua força e coragem ao perder o braço na brincadeira.

Aos poucos, Hugo passa a exercer sua capacidade de reparação, mostrando estar se responsabilizando pelo aspecto agressivo de sua natureza, isso aparece sob a forma de um brincar construtivo com blocos de madeira e por meio da brincadeira de médico.

Hugo encontra a possibilidade de assumir papéis que não são permitidos na vida real e extrai benefícios disso. Utiliza sua capacidade de preocupar-se e fazer reparações, permitindo que encontre formas de lidar com sua agressividade. Nas brincadeiras de massinha, Hugo encontra a possibilidade de elaborar seus conteúdos anais.

Ao escolher brincar com o quebracabeça, mostra interesse por desafios intelectuais, reafirmando, por meio da atividade lúdica, suas habilidades cognitivas e sua capacidade de aprender.

O menino revela, ainda, sua capacidade criativa. Ao desenhar, mostra-se disponível para atividades projetivas. Além disso, faz o convite para acompanhá-lo na atividade, denotando a existência de um vínculo e o interesse em estreitá-lo.

Ao realizar o desenho, acredita-se que Hugo expresse algumas fantasias sobre si mesmo e sua relação com o irmão. Ao desenhar-se em um rio, possivelmente Hugo manifeste a elaboração de algum conflito, simbolizando sua transição para um nível de desenvolvimento mais elevado. No desenho, o menino ainda demonstra compreender ou desejar que seu irmão encontrese em um nível de desenvolvimento inferior ao dele, uma vez que aquele não tem coragem de atravessar o rio, preferindo colher frutos que estão no chão.

Ao brincar de comidinha, ofertando-me diversos tipos de alimentos, Hugo demonstra coisas boas que é capaz de produzir, o que pode estar ligado à necessidade e capacidade de reparação. 


\section{CONCLUSÃO}

Por meio dos relatos e reflexões aqui apresentados, pode-se observar que Hugo encontrou na brincadeira e nas conversas a possibilidade de elaborar seus conflitos e suas angústias, assumir papéis e vivenciar situações que não se permitia na vida real e em suas relações interpessoais.

Hugo demonstra a capacidade de estabelecer um vínculo de confiança duradouro e de se beneficiar com isso, por meio do desenvolvimento de atividades projetivas, nas quais manifesta sua capacidade criadora, utilizando a fantasia como forma de expressão de seus desejos e conflitos inconscientes.

No decorrer dos atendimentos, nota-se uma evolução do brincar. Inicialmente, as brincadeiras desenvolvidas pelo garoto são marcadas fortemente pela descarga de agressividade. Encontrar essa possibilidade de expressar suas tendências destrutivas por meio de símbolos é justamente o que contribuiu para a evolução dessas atividades, que, aos poucos, passaram a conter aspectos reparadores e construtivos.

Acredita-se que as atividades lúdicas trouxeram impactos na autoestima de Hugo, bem como maior tranquilidade em suas relações interpessoais. $\mathrm{O}$ vínculo que estabeleceu comigo nas seções lúdicas também foi componente importante para propiciar ou catalisar as transformações nele observadas e que, conforme relato da professora, foram percebidas também em sala de aula, portanto, em um contexto de espaço e tempo diverso daquele em que desenvolveu atividades lúdicas.

\section{REFERÊNCIAS}

LÜDKE, M.; ANDRÉ, M. E. D. A. Pesquisa em Educação: abordagens qualitativas. São Paulo: EPU, 1986.

WINNICOTT, D. W. A criança e o seu mundo. 6. ed. Rio de Janeiro: LTC, 1982.

WINNICOTT, D. W. Da pediatria à psicanálise: obras escolhidas. Rio de Janeiro: Imago,2000.

WINNICOTT, D. W. Natureza Humana. Rio de Janeiro: Imago, 1990.

WINNICOTT, D. W. Privação e delinqüência. 4. ed. São Paulo: Martins Fontes, 2005.
Recebido para publicação em 17/08/2016

Revisado em 19/08/2016

Aceito em 20/08/2016 